\title{
Perineal Endometriosis in an Episiotomy Scar- A Rare Case Report
}

\author{
Mahendra Singh ${ }^{1}$, Jagdish kumar $^{2}{ }^{*}$, Anita Omhare ${ }^{3}$, Neelima Verma ${ }^{4}$ \\ ${ }^{1}$ HOD, Department of Pathology, G.S.V.M. Medical College, Kanpur, U.P, India \\ ${ }^{2}$ Junior Resident, Department of Pathology, G.S.V.M. Medical College, Kanpur, U.P, India \\ ${ }^{3}$ Assistant Professor, Department of Pathology, G.S.V.M. Medical College, Kanpur, U.P, India \\ ${ }^{4}$ Associate Professor, Department of Pathology, G.S.V.M. Medical College, Kanpur, U.P, India
}

*Address for Correspondence: Dr. Jagdish Kumar, Junior Resident, Department of Pathology, G.S.V.M. Medical College, Kanpur, India

E-mail: kumarjagdish791@gmail.com

Received: 03 June 2018/ Revised: 17 Oct 2018/ Accepted: 17 Dec 2018

\begin{abstract}
Background: Perineal endometriosis is a rare disease characterized by the presence of ectopic endometrial stroma and glands in the perineum with an incidence rate of $0.31 \%$. Most commonly observed in the episiotomy scar after normal vaginal deliveries and perineal, it is not often considered in the differential diagnosis of perineal masses. This could lead to unnecessary investigations and inadequate patient treatments.

Methods: A 25-year-old woman with complaints of a tender perineal mass, which became hard and more painful during menses. Her symptoms started since 6 months back. Previously on the same site, where a midline episiotomy was performed during the normal vaginal delivery. Complete surgical excision of the perineal mass was performed and the histopathology report confirmed perineal endometriosis. No recurrence was noted on the postoperative course.

Results: On histopathological examination of resected mass perineal scar endometriosis was conformed.

Conclusion: A comprehensive history and meticulous pelvic examination are essential in diagnosing perineal endometriosis. Surgical intervention is the best approach for treatment and histopathological examination for confirmation. Permanent cure is usually achieved after complete excision of the perineal endometriosis. We presented this case due to rare incidence and to differentiate it from other perineal masses.
\end{abstract}

Key-words: Episiotomy, Endomaterial gands, Perineal endometriosis, Perineal mass, Vaginal delivery

\section{INTRODUCTION}

Endometriosis is a benign disease defined by the presence of endometrial glands and stroma in anatomic locations other than the uterine lining ${ }^{[1]}$. It is most commonly observed in the dependent portions of the pelvis, and most frequently on the peritoneal surfaces of the ovaries, uterosacral ligaments, and other pelvic organs. Endometriosis can also be found anywhere in the body such as the thoracic cavity, urinary and intestinal tracts, inguinal canal, umbilicus, surgical scars, and the perineum. The incidence of perineal endometriosis is

\section{How to cite this article}

Singh M, kumar J, Omhare A, Verma N. Perineal Endometriosis in an Episiotomy Scar- A Rare Case Report. SSR Inst. Int. J. Life. Sci., 2019; 5(1): 2137-2139.

\begin{tabular}{|c|c|}
\hline & Access this article online \\
\hline & www.ijlssr.com
\end{tabular}

rare, possibly because of underreporting. Its significance in clinical practice is arguable. In a review of the literature, only case reports and case series have been reported. Between 1983 and 2007, the incidence of perineal endometriosis was $0.31 \%$ among women with endometriosis treated surgically ${ }^{[1]}$. The rarity of cases may be because of the fact that perineal endometriosis may not have been included in the differential diagnosis of perineal masses, which may have led to underreporting and inadequate patient treatment.

\section{CASE REPORT}

A-25-year old woman presented in the obstetrics and gynecology OPD at G. S. V. M. Medical College Kanpur U.P. India with complains of perineal mass and pain for 6 months. Pain increased during menses. She also gave a history of dyspareunia and itching over the perineal region. There was a history of vaginal delivery with episiotomy 1 year back. 
On local, examination a mass was present at perineum near the episiotomy site. On the basis of history and examination scar endometriosis mass suspected. After routine laboratory investigation, surgical excision of the mass was done under spinal anesthesia and the specimen was sent to the pathology department for histopathological examination.

Gross findings- Specimen consists of multiple greyish white to greyish brown soft to firm tissue pieces altogether measuring $2 \times 1.5 \mathrm{~cm}$. Whole tissue was processed. Paraffin blocks made and tissue sections were stained with hematoxylin and eosin for microscopic examination.
Microscopic findings- Section shows fragmented tissue piece lined by keratinized, hyperplastic stratified squamous epithelium. Underlying fibro-collagenous stroma shows few endometrial glands with scanty stroma. Glands are lined with low columnar epithelial cells. A Section also shows multiple hair follicles, pilosebaceous units, multiple small proliferating thinwalled blood vessels, subcutaneous fatty tissue and dense inflammatory cell infiltrate comprising of lymphocytes, macrophages, and neutrophlis. One cystic space seen lined by low cuboidal to flattened epithelium filled with hemorrhage and inflammatory cell infiltrate comprising of lymphocytes, macrophages, and neutrophlis. Few smooth muscle bundles were also seen.

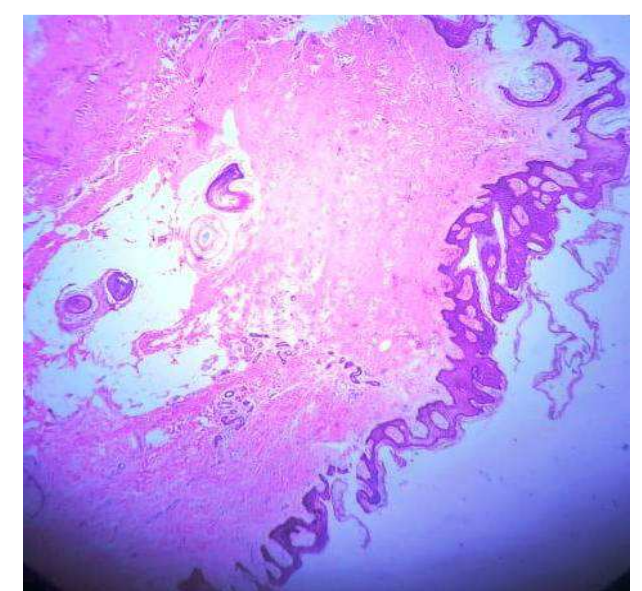

Fig. 1: Showing fibro-collagenous tissue piece covered with stratified squamous epithelium (40X H \& E)

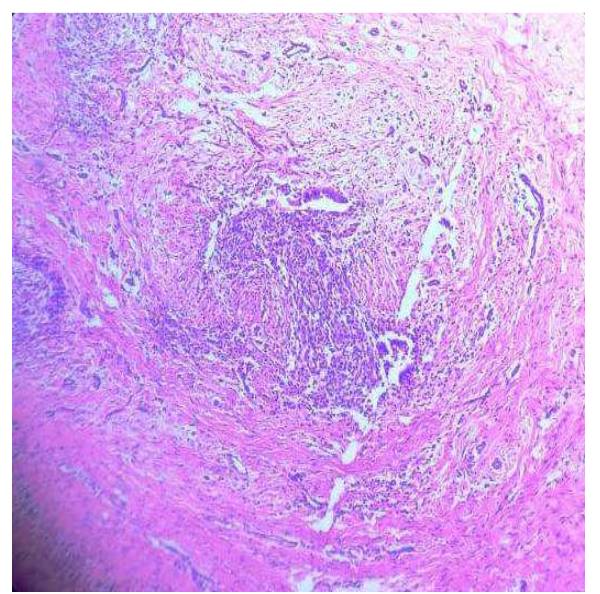

Fig. 2: Showing multiple endometrial glands with stroma (100X H \& E)

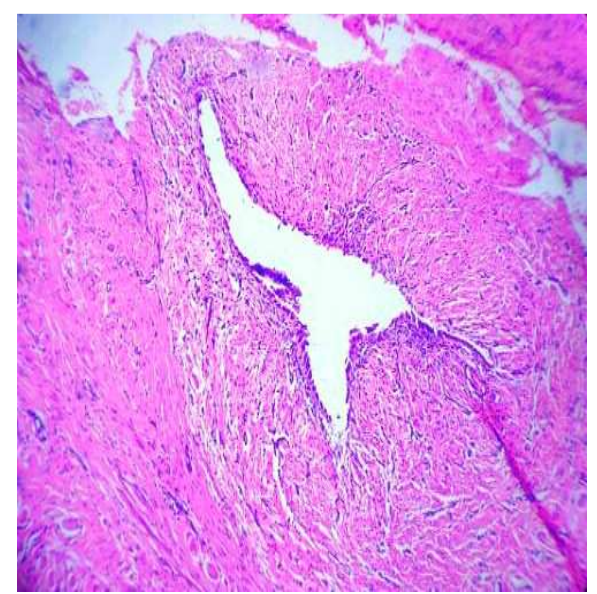

Fig. 3: Showing dilated endometrial gland (400X H \& E)

\section{DISCUSSION}

Scar endometriosis is a rare entity. The incidence has been estimated to be only $0.03-0.15 \%$ of all cases of endometriosis ${ }^{[1]}$. The incidence of episiotomy scar endometriosis was estimated to be 15 of 2028 consecutive deliveries ${ }^{[2]}$. Patil et al. ${ }^{[3]}$ were studied 17 cases of extrapelvic endometriosis in a time span of 15 years and found a total of three cases of episiotomy scar endometriosis. Luterek et al. ${ }^{[4]}$ reported a case of a 33-year-old woman with a medical history of recurrent perianal endometriosis. An endometriotic giant mass ( $8 \mathrm{~cm}$ in diameter) was widely excised together with the episiotomy scar. They concluded that a wide excision is mandatory as it is the only way to prevent tumor recurrence $^{[4]}$.
Treatment of choice is wide excision of the lesion and medical management if required. Only medical treatment with the use of progestogen, oral contraceptive pills, and danazol is not effective and gives only partial relief in symptoms. Recently, there has been a report of use of gonadotropins agonist but only with prompt improvement in symptoms with no change in the lesion size. These patients need to be followed up because of the chances of recurrence, which require re-excision. In the case of continual recurrence, the possibility of malignancy should be kept in mind ${ }^{[5]}$.

A tender nodule or perineal mass, accompanied by progressive and cyclic perineal pain in a patient with a history of an episiotomy, is highly diagnostic ${ }^{[6]}$. Physical examination usually reveals a tender bluish perineal mass. Previously reported cases consistently describe these physical exam\findings. Symptoms usually appear 
shortly after ectopic endometrial cell implantation, with some cases having a prolonged latent period of up to 14 years after implantation ${ }^{[7]}$.

\section{CONCLUSIONS}

The perineal scar endometriosis was confirmed by the histopathological examination. Patient was asymptomatic since surgical management. We had reported this case because of rare incidence and perineal scar endometriosis should be included in the differential diagnosis of perineal masses if associated with cyclical pain and a history of childbirth so that adequate treatment and follow-up can be done.

\section{ACKNOWLEDGMENTS}

All authors very thankful to the Department of Pathology, G.S.V.M. Medical College Kanpur, India for help in writing the paper.

\section{CONTRIBUTION OF AUTHORS}

Research concept- Dr. Mahendra Singh, Dr. Jagdish kumar

Research design- Dr. Jagdish kumar

Supervision- Dr. Mahendra Singh

Materials- Dr. Anita Omhare, Dr. Neelima Verma

Data collection- Dr. Jagdish kumar

Data analysis- Dr. Jagdish kumar

Literature search- Dr. Jagdish kumar

Writing article- Dr. Jagdish kumar

Critical review- Dr. Mahendra Singh

Article editing- Dr. Anita Omhare, Dr. Neelima Verma

Final approval- Dr. Mahendra Singh, Dr. Jagdish kumar

\section{REFERENCES}

[1] Francica G, Giardiello C, Angelone G, et al. Abdominal wall endometriosis near cesarean delivery scars. J. Ultrasound Med., 2003; 22: 104147.

[2] Paul T, Tedeschi LG. Perineal endometriosis at the site of episiotomy scar. Obstet. Gynecol., 1972; 40: 28-34.

[3] Patil BS, Tripathi JB, Patil FB, et al. Extra pelvic endometriosis: A study of 17 cases. J. South Asian Fed. Obster. Gynecol., 2012; 4(1): 32-34.

[4] Luterek K, Barcz E, Bablok L, et al. Giant recurrent perineal endometriosis in an episiotomy scar- A case report. Ginekol. Pol., 2013; 84(8): 726-29.

[5] Park SW, Hong SM, Wu HG, et al. Clear cell carcinoma arising in a cesarean section scar endometriosis. J. Korean Med. Sci., 1999; 14: 217-19.

[6] Zhu L, Lang JH, Xin F, et al. The diagnosis and treatment of perineal endometriosis. Chin. J. Obstet. Gynecol., 2002; 37: 53-64.

[7] Kinkel K, Frei KA, Balleyguier C, Chapron C. Diagnosis of endometriosis with imaging: A review. Eur. Radiol. 2006; 16: 285-98. 